\title{
JOINT LAXITY IN IDIOPATHIC ADOLESCENT SCOLIOSIS
}

\author{
MALCOLM BINNS \\ From the Duchess of Kent Children's Hospital, Hong Kong
}

\begin{abstract}
Joint laxity was quantified by measuring the distance from the thumb tip to the forearm during passive apposition in $\mathbf{5 0 0}$ normal Southern Chinese women. Joint laxity was found to have a normal distribution throughout the population and to decrease with age. When 109 Chinese girls with idiopathic adolescent scoliosis were similarly tested they were found to have significantly more laxity, suggesting that the two conditions are associated.
\end{abstract}

Scoliosis occurs in association with conditions that manifest excessive laxity of the joints (Ehlers-Danlos syndrome, Marfan's syndrome, osteogenesis imperfecta and homocystinuria). Joint laxity varies throughout the population and appears to have a Gaussian distribution (Kirk, Ansell and Bywaters 1967; Bird 1986). Beighton and Horan (1970) suggested that hyperlaxity is transmitted as an autosomal dominant trait which characterises a second group of individuals apart from those at the extreme end of a normal distribution.

Joint laxity is determined in part by capsular viscoelasticity which reflects collagen and proteoglycan structure. Abnormal collagen type with reduced crosslinking (Smith and Francis 1974; Sanderson, Francis and Smith 1978) as well as deranged glycosaminoglycan metabolism (Nordwall and Waldenström 1976; Ponseti et al. 1976) have been demonstrated in idiopathic scoliosis; thus laxity may predispose to spinal instability and the development of scoliosis. Joint laxity is also associated with other skeletal instabilities such as congenital dislocation of the hip (Carter and Wilkinson 1964; Wynne-Davies 1970).

Generalised joint laxity has been measured using a scoring system of five parameters (Beighton, Solomon and Soskolne 1973; Wynne-Davies 1973): knee and elbow hyperextension of more than $10^{\circ}$, hyperextension of the wrist with the fingers parallel to the forearm, dorsiflexion of the ankle beyond $45^{\circ}$ and passive apposition of the thumb to the forearm. Three or more paired joints demonstrating this degree of laxity is positive for a "hyperlaxity syndrome".

It is difficult to assess the end point of each test, especially hyperextension beyond $10^{\circ}$. Such a qualitative

M. S. Binns, DCH, MCh Orth, FRCS Ed(Orth), Formerly Fellow, University of Hong Kong

Present address: 50 Barwell Lane, Hinckley, Leicestershire LE10 ISS, England.

(C) 1988 British Editorial Society of Bone and Joint Surgery $0301-620 X / 88 / 3081 \$ 2.00$

J Bone Joint Surg [Br] 1988;70-B:420-2. scoring system identifies the hyperlax group but does not quantify the variation of joint laxity throughout the population. If we assume that the degree of laxity for all joints is the same then measuring passive thumb-toforearm apposition provides a measure of generalised joint laxity.

\section{PATIENTS AND METHODS}

Joint laxity was measured by recording the average distance in centimetres of the middle of the thumb nail to the forearm during passive wrist flexion and thumb apposition. Five hundred girls and women attending fracture clinics were tested (Fig. 1), and the average distance to the nearest $0.5 \mathrm{~cm}$ was recorded. Joint laxity in 109 girls attending a scoliosis clinic with a diagnosis of idiopathic adolescent scoliosis was recorded by the same method. The age of initial presentation with scoliosis, age at the time of assessment of laxity, the site of the scoliotic curve, degree of deformity (Cobb angle), treatment regime and standing height were recorded.

As thumb length influences its distance to the forearm, hand span was recorded in both groups: this was the measurement between the thumb and little finger during wide abduction of all fingers. All subjects were Southern Chinese (Cantonese).

\section{RESULTS}

Figure 2 shows the thumb-to-forearm distance, which increases with age, the rate of increase lessening after about 16 years. Hand span also increases, reaching a maximum at about 18 years. Figure 3 shows, in patients over 16 years of age, the thumb-to-forearm distance to the nearest one centimetre. There is a Gaussian distribution skewed for age, with an additional hyperlax group showing complete thumb apposition to the forearm.

Joint laxity in the scoliotic patients fell into two distinct groups: 61 patients $(56 \%)$ who demonstrated complete thumb apposition to the forearm, and the 


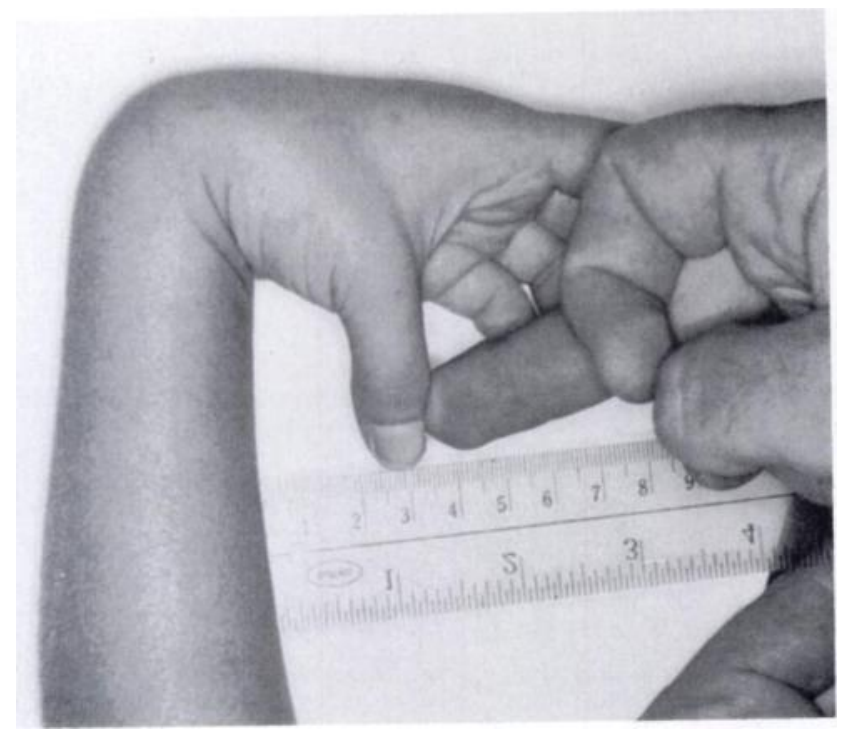

Fig. 1

Measurement of thumb-to-forearm distance

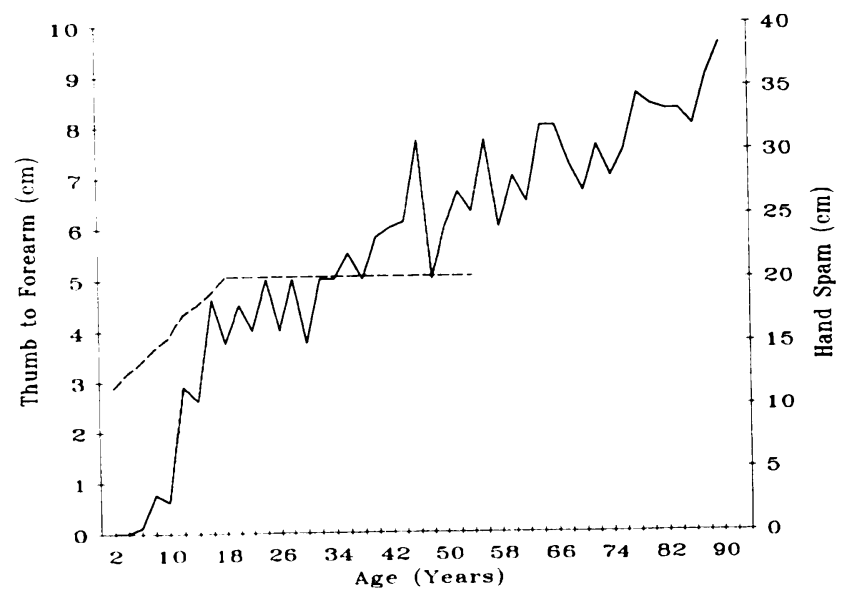

Fig. 2

Changes in thumb-to-forearm distance and hand span with age in normal subjects.

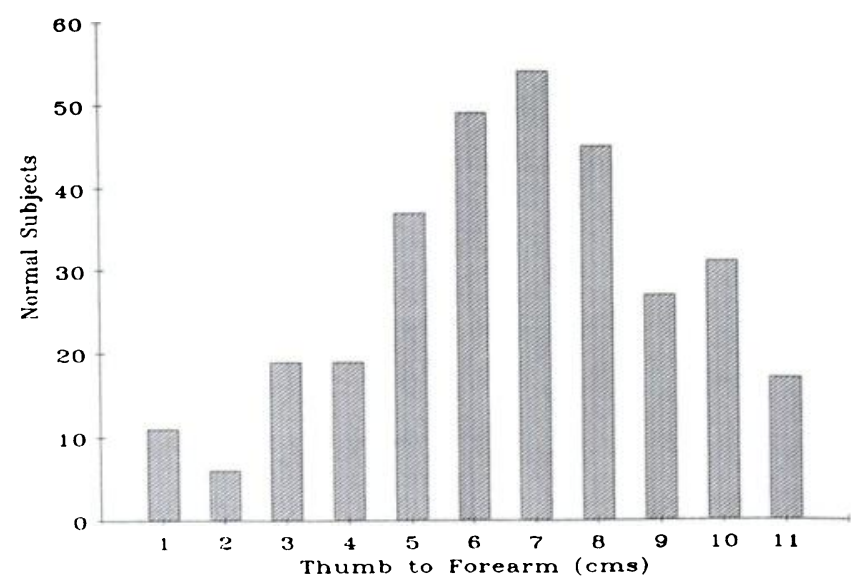

Fig. 3

The distribution of thumb-to-forearm distance in normal subjects over the age of 16 years. remaining 48 patients who average $2.0 \mathrm{~cm}$ thumb-toforearm distance. These values are significantly less than those of the normal population who average $4.25 \mathrm{~cm}$ at the age of 17.5 years. The hand span of all scoliotics averaged $20 \mathrm{~cm}$ and was no different from that of the normal population.

There was no significant difference between the hyperlax group and the remainder in the presenting or assessment age, Cobb angle, site of the curve, treatment modality or standing height.

\section{DISCUSSION}

The thumb-to-forearm distance measured during passive apposition in patients with idiopathic adolescent scoliosis suggests that they are relatively hyperlax. The two groups that emerge are those at the extreme of normal distribution and those that are hyperlax, showing the "joint hyperlaxity syndrome"; this reflects but exaggerates a trend in the normal population. Normal subjects show a rapid decrease in joint laxity in childhood with a slower decrease in adulthood (Beighton et al. 1973).

Joint laxity is not totally determined by capsular properties. Johns and Wright (1962) in a rheological study of the cat's wrist showed that the capsule contributed $47 \%$ and muscle $41 \%$ resistance to passive movement. Muscle tone decreases with age, joint stiffness increases with age and this suggests that soft tissues are the major determinant of joint laxity.

Animal experiments have shown that disruption of the costo-transverse spinal ligaments produces scoliosis (Langenskiöld and Michelsson 1962). Olsen and Allan (1969) drew attention to paired diagonal intercostal ligaments as an intermediate truss system supporting ribs and thoracic spine. Mehta (1972), in describing the ribvertebra angle difference as a prognostic sign for curve progression in infantile curves, suggested that costovertebral ligaments weakened by a generalised soft-tissue disorder would yield more readily to deforming forces. Enneking and Harrington (1969), in a pathological study of scoliosis, concluded that the deformity was produced by an extra-osseous cause and that other changes were secondary. Dickson and Archer (1986), reporting studies on the three-dimensional nature of scoliosis, suggested that idiopathic scoliosis represented a lordoscoliosis in reduced spinal mechanical integrity.

Veliskakis (1973) described a high incidence of hyperlaxity in the families of children with idiopathic scoliosis, but hyperlaxity in the children themselves compared with a matched population has not previously been described.

Whatever the primary pathology of idiopathic scoliosis it seems that those individuals who manifest hyperlaxity may be more likely to progress to scoliotic deformity, presumably because of reduced spinal integrity.

The author would like to thank Dr L. Hsu for his help and advice. 


\section{REFERENCES}

Beighton P, Solomon L, Soskolne CL. Articular mobility in an African population. Ann Rheum Dis 1973;32:413-8.

Beighton PH, Horan FT. Dominant inheritance in familial generalised articular hypermobility. J Bone Joint Surg [Br] 1970;52-B:145-7.

Bird HA. A clinical review of the hyperlaxity of joints with particular reference to osteoarthrosis. Eng Med 1986;15:81-5.

Carter C, Wilkinson J. Persistent joint laxity and congenital dislocation of the hip. J Bone Joint Surg [Br] 1964;46-B:40-5.

Dickson RA, Archer IA. Biomechanics of spinal deformity. J Bone Joint Surg $[\mathrm{Br}]$ 1986;68-B:682.

Enneking WF, Harrington P. Pathological changes in scoliosis. $J$ Bone Joint Surg [Am] 1969;51-A:165-84.

Johns PJ, Wright V. Relative importance of various tissues in joint stiffness. J Appl Physiol 1962;17:824-8.

Kirk JA, Ansell BM, Bywaters EGL. The hypermobility syndrome: musculoskeletal complaints associated with generalized joint hypermobility. Ann Rheum Dis 1967;26:419-25.

Langenskiöld A, Michelsson J-E. The pathogenesis of experimental progressive scoliosis. Acta Orthop Scand 1962: Suppl 59.

Mehta MH. The rib-vertebra angle in the early diagnosis between resolving and progressive infantile scoliosis. J Bone Joint Surg [Br] $1972 ; 54-B: 230-43$.
Nordwall A, Waldenström J. Metachromasia of fibroblasts from patients with idiopathic scoliosis. Spine 1976;1:97-8.

Olsen GA, Allan JH. The lateral stability of the spine. Clin Orthop $1969 ; 65: 143-56$.

Ponseti IV, Pedrini V, Wynne-Davies R, Duval-Beaupere G. Pathogenesis of scoliosis. Clin Orthop 1976;120:268-80.

Sanderson MC, Francis MJO, Smith R. Skin collagen in scoliosis. $J$ Bone Joint Surg [Br] 1978;60-B:291.

Smith R, Francis MJO. Polymeric collagen of skin and idiopathic adolescent scoliosis. In: Zorab PA, ed. Scoliosis and muscle Proceedings of the fourth symposium held at the Cardiothoracic Institute, Brompton Hospital, London, on 14th and 15th November 1973. (Spastics International Medical Publications, Research Monograph No. 4.) London: Heinemann Medical. Philadelphia: JB Lippincott, 1974:62-4.

Veliskakis KP. Increased generalized ligamentous laxity in idiopathic scoliosis. J Bone Joint Surg [Am] 1973;55-A:435.

Wynne-Davies R. Acetabular dysplasia and familial joint laxity: two etiological factors in congenital dislocation of the hip: a review of 589 patients and their families. J Bone Joint Surg $[\mathrm{Br}]$ 1970;52-B:704-16.

Wynne-Davies R. Heritable disorders in orthopaedic practice. Oxford, etc: Blackwell Scientific, 1973:138. 